\title{
LA ESCOLÁSTICA MEDIEVAL EN LOS ESCRITOS CONFESIONALES DEL LUTERANISMO
}

MANFRED SVENSSON

Universidad de los Andes, Chile

\begin{abstract}
RESUMEN: El artículo busca establecer la presencia de elementos de la escolástica medieval en los escritos confesionales del luteranismo. Por esta vía se busca alcanzar algunas precisiones sobre la continuidad en este periodo de la historia intelectual, así como iluminar también el tipo de valoración de la actividad filosófica por parte de los reformadores.
\end{abstract}

PALABRAS CLAVE: Libro de Concordia, Lutero, Melanchthon, escolástica

\section{Medieval Scholasticism in the Lutheran Confessional Writings}

ABSTRACT: The present article is a survey of medieval scholastic ideas in the confessional writings of the Lutheran Church. It thus seeks to shed further light on the continuity of intellectual history in the Sixteenth Century, as well as on the Reformation theologians' view of philosophical reasoning.

KEY WORDS: Book of Concord, Luther, Melanchthon, scholasticism.

\section{INTRODUCCIÓN}

Si bien en ocasiones se reconoce elementos de continuidad de los reformadores con ciertas tradiciones de la espiritualidad medieval, no suele ocurrir lo mismo con el pensamiento medieval. La parte mayor de la literatura relativa a las reformas del siglo XvI aborda predominantemente los aspectos de ruptura en la relación entre el protestantismo y la tradición medieval. El presente artículo busca cubrir una pequeña parte de la tarea pendiente en relación con la continuidad, prestando atención a la presencia de la tradición medieval no en la obra de un autor determinado, sino en los escritos confesionales del luteranismo, esto es, los documentos oficiales de confesión de fe, desde la Confesión de Ausburgo escrita por Melanchthon en 1530 hasta la Fórmula de Concordia por la que en 1577 se resuelven las controversias intraluteranas posteriores a la muerte de Lutero. Los motivos para ocuparse de este problema son por supuesto múltiples. Una recta aproximación a este problema puede, en efecto, tener cierta relevancia ecuménica, pero puede también ser clarificadora para la autocomprensión del protestantismo en lo que respecta tanto a su relación con la tradición como a su relación con la razón, y es, por último, una tarea indispensable para quien esté interesado en una ecuánime presentación de los puntos de continuidad y ruptura de la historia intelectual de Occidente $^{1}$. La Reforma protestante, en efecto, ocupa para muchos autores un importante puesto en la genealogía de la modernidad, cuestión comprensible si se la estudia como movimiento emancipatorio. Pero dicho lugar le suele ser asignado precisamente haciendo caso omiso del tipo de textos que aquí tratamos.

Antes de entrar al análisis detallado, corresponde explicar por qué me he limitado en el presente trabajo a los escritos confesionales del luteranismo en lugar de incluir

\footnotetext{
1 La bibliografía sobre su papel en tal quiebre es abrumadora. Con todo, sigue siendo un punto de referencia imprescindible Troeltsch, E. Die Bedeutung des Protestantismus für die Entstehung der modernen Welt en Ernst Troeltsch, Kritische Gesamtausgabe vol. 8, Walter de Gruyter, Berlín, 2001.
} 
a otras tradiciones protestantes. Son dos los argumentos principales que me han llevado a tal decisión. El principal es el momento en que fueron escritas las principales confesiones de fe de tradición calvinista. Al menos las más elaboradas de éstas son, en efecto, casi un siglo posteriores a las luteranas. La Confesión de Fe de Westminster, por ejemplo, data de 1647. El carácter temprano que en contraste con eso tienen los escritos confesionales luteranos, permite de antemano responder a una eventual objeción contra elementos «escolásticos» en la tradición del protestantismo confesional de los siglos XVI y XVII. En efecto, es un modelo típico de interpretación el reconocer en este período la presencia de elementos vagamente identificados como "medievales» o "escolásticos», pero al mismo tiempo interpretar dicho fenómeno como una «recaída» que traiciona el movimiento original de la Reforma ${ }^{2}$. Tal interpretación puede ser objeto de variadas objeciones $^{3}$, pero son objeciones a las que no será necesario entrar aquí, puesto que si nos concentramos en la tradición luterana, no existe siquiera el lapso de tiempo necesario para hacer plausible una «recaída». En efecto, el Libro de Concordia, el documento que contiene todos los documentos confesionales en los que aquí nos detendremos, fue publicado en 1580, y en él se encuentran textos que datan de 1530 a 1577, lo cual nos sitúa dentro de la primera y segunda generación de la Reforma.

El segundo argumento tiene relación con la diversa naturaleza de los textos confesionales de las tradiciones luterana y calvinista. Los textos de la tradición calvinista son no sólo más tardíos, sino también más uniformes en su autoría y más austeros en las referencias. La Confesión de Fe de Westminster no incluye, por ejemplo, referencia expresa a pensador alguno, aunque se pueda diagnosticar la mayor o menor presencia de determinadas corrientes teológicas en ella. En contraste con esto, el Libro de Concordia constituye un conjunto de textos de naturaleza muy distinta: en él encontramos una simple confesión de fe como la Confesión de Ausburgo — comparable a la de Westminster-, pero también la Apología de la Confesión de Ausburgo que Melanchthon escribiera al año siguiente, dos textos polémicos de Lutero - los artículos de Esmalcalda y el tratado sobre la primacía del papa-, los dos catecismos de Lutero, y la Fórmula de Concordia, un texto escrito en coautoría por varios autores, que zanja las controversias intraluteranas posteriores a la muerte de Lutero. En este conjunto de textos la presencia de la tradición intelectual cristiana previa es muy variada. Tal variación se debe en parte a los distintos géneros literarios usados, que se prestan unos más que otros para hacer alusiones a autores del pasado: la Apología de la Confesión de Ausburgo se presta por ejemplo más que la Confesión misma para mostrar quiénes en el pasado pueden ser invocados como aliados. Por otra parte, los textos proceden de autores distintos, y esto nos permite evaluar en qué medida los casos de crítica o apropiación de la tradición medieval se deben a diferencias individuales y en qué medida, por el contrario, nos encontramos con aproximaciones características de toda una tradición.

Para ofrecer un panorama adecuado intentaré, en primer lugar, aclarar cómo se ve desde los propios textos confesionales la delimitación del periodo: en qué medida hay en ellos una noción de lo medieval y de lo escolástico, y de dónde a dónde se extenderían. En segundo lugar, atenderé a tópicos específicos de controversia que permiten estudiar el trato dado a los autores medievales. Así, abordaré sucesivamente la acusación de

2 Para una exposición de este tenor, aún influyente entre pensadores protestantes contemporáneos, puede verse Dooyeweerd, H. Las raíces de la cultura occidental Clie, Barcelona, 1998.

3 La más contundente respuesta a las críticas a la escolástica protestante se encuentran en la monumental obra de Muller, R. A. Post-Reformation Reformed Dogmatics 4 vols., Baker Academic, Grand Rapids, 2003. 
pelagianismo, la distinción entre la justicia civil y la justificación por la fe y, por último, las apelaciones a la razón.

\section{LA DELIMITACIÓN DEL FENÓMENO}

En primer lugar, se hará aquí el intento por delimitar el campo de estudio desde los mismos escritos confesionales. Esto es, antes de atender a la apropiación o a la crítica, veremos qué entiende el mismo Libro de Concordia bajo autores escolásticos, y cómo delimita el periodo. Conviene, por cierto, notar, que «escolástica»y «filosofía medieval» no son expresiones equivalentes, ni son usadas en el periodo a estudiar siempre en el mismo sentido que le damos hoy. Los reformadores carecen, de partida, de una noción de Edad Media, y naturalmente no pueden tampoco tener la conciencia que hoy tenemos del hecho de que «escolástica» hace referencia no a un conjunto de tesis, sino más bien a un método teológico y filosófico específico. Se trata, en efecto, como crecientemente lo reconocen los estudios de la escolástica y de la filosofía medieval, de términos que no son coextensivos: hay filosofía medieval más allá de la escolástica y hay escolástica más allá del periodo medieval ${ }^{4}$.

Tal precisión no ha de esperarse en los reformadores, pero sí cabe preguntarnos cuán indiferenciado es su uso de categorías como "escolástica», esto es, en qué medida en los escritos confesionales se reconoce una pluralidad de escuelas escolásticas, y en qué medida tal eventual reconocimiento es un factor para una evaluación diferenciada de las mismas. Con todo, la respuesta final a dicha pregunta sólo se podrá dar tras haber abordado algunos problemas de tipo sistemático en otras secciones.

La expresión "scholastici» es bastante frecuente en el Libro de Concordia, y hace invariablemente referencia a autores escolásticos, no a su otra acepción, la de estudiantes. Aparecen también en la obra términos alternativos para referirse a las escuelas medievales, algunos de los cuales pueden ser estrictamente descriptivos - como «Sentenciarios» ${ }^{5}$ para referirse a los comentadores de Lombardo- otros en cambio despectivos — como "sofistas» ${ }^{6}$. La primera observación que cabe hacer aquí, es que en medio de estos epítetos no existe referencia alguna a lo medieval ni a la Edad Media. Cuando hay en estos escritos una división entre épocas, se trata siempre de la división entre «antiguos» y «modernos». Dentro de tal división, los autores que nosotros llamamos medievales suelen ser clasificados entre los «modernos» o recentiores ${ }^{7}$, un punto importante a tener en mente para evaluar la autocomprensión de los reformadores.

4 Respecto de esto véase sobre todo LeINSLE, U. Introduction to Scholastic Theology Washington, CUA Press, 2010 .

5 BSLK 182 pone sententiarii en latín y la versión alemana conserva el latín sententiarios. Lo mismo en BSLK 173. A lo largo de este artículo los escritos confesionales son citados según la edición estándar, Die Bekenntnisschriften der Evangelisch-Lutherischen Kirche (BSLK) Vandenhoeck \& Ruprecht, Göttingen 1967. A la vista se ha tenido también la edición española Libro de concordia Editorial Concordia, San Luis, 1989, cuyas notas solo incluyen una selección del aparato de la edición alemana. También se ha tenido a la vista la edición inglesa preparada por Robert Kolb y Timothy Wengert, The Book of Concord: The Confessions of the Evangelical Lutheran Church Fortress Press, Minneapolis, 2000, cuyas introducciones y notas sí innovan respecto de la edición alemana.

6 BSLK 219.

7 BSLK 375. Para esta designación entre los humanistas véase BEJCZY, I. Erasmus and the Middle Ages: the Historical Consciousness of a Christian Humanist Brill, Leiden, 2001. pág. xv. 
Atendamos a algunos casos específicos. De todo el Libro de Concordia, sólo la Fórmula de Concordia contiene una referencia simultánea a «teólogos antiguos y modernos». Ésta se encuentra en el comienzo de la sección, para señalar que unos y otros pueden valer como testigos, más no como jueces en las controversias teológicas ${ }^{8}$. No parece pues que se pueda hablar de una actitud precipitadamente favorable a antiguos o modernos. Desde observaciones como ésta cabría responder no sólo a quienes ven en la Reforma un abandono de la tradición, sino también a quienes — como Nietzsche y Ortega y Gasset ven en ella solo primitivismo ${ }^{9}$. A renglón seguido, en efecto, se declara que tanto entre los antiguos como entre los modernos existe ocasionalmente un lenguaje que no puede ser seguido ${ }^{10}$. Esto indica cierta noción básica, aunque sea en estado germinal, de desarrollo doctrinal legítimo: no son las enseñanzas de los autores previos las que son objeto de la crítica, sino la imprecisión de su lenguaje; tal imprecisión puede haber sido legítima antes de las controversias del siglo xvI, pero no lo es una vez que un conflicto doctrinal obliga a una fijación terminológica más estricta. La raíz de esto puede por supuesto ser "anticatólica», pero quien conozca a Newman reconocerá la catolicidad de la estructura del argumento ${ }^{11}$.

Ahora bien, la Fórmula comienza también señalando que su objeto es dirimir controversias de la actualidad, y así no ha de extrañar si se da preponderancia a errores «modernos». ¿Pero quiénes son estos autores antiguos y modernos? En la Apología de la Confesión de Ausburgo encontramos la primera mención que nos permite resolver tal duda. Melanchthon describe ahí las discusiones de los modernos como sofísticas ${ }^{12}$, lo que haría parecer que en él la actitud no es muy diferenciada. Tomás de Aquino, de hecho, es aludido como uno de los autores «modernos» ${ }^{13}$. Pero esta impresión cambia si atendemos al hecho de que Tomás de Aquino es presentado como uno de los «modernos prudentes ${ }^{14}$. De hecho, aunque la expresión está en plural, Tomás de Aquino es el único ejemplo mencionado en todo el Libro de Concordia bajo tal rótulo. Entre los «modernos» se establece pues distinciones, por menores que éstas sean.

En cuanto al período de inicio de esta «modernidad», los distintos textos que componen el Libro de Concordia difieren entre sí. Por una parte están los autores de la Fórmula de Concordia, que trabajan con criterios más parecidos a los que usaríamos hoy. Así se puede ver en dos listados que ofrece la Fórmula, uno de «doctores antiguos» que termina con Gelasio (muerto 496) ${ }^{15}$, y otro de «antiguos doctores de la iglesia» que termina con Juan Damasceno (muerto 749) ${ }^{16}$. Clasificaciones similares son fáciles de encontrar en patrologías de hoy, con autores como éstos como respectivos límites occidentales y orientales.

\section{$8 \quad$ BSLK 768}

9 Véase Ortega y Gasset, J.: La idea de principio en Leibniz Alianza, Madrid, 1992. pág. 369. Ortega y Gasset remite para esta interpretación de la Reforma al En torno a Galileo de Nietzsche.

10 BSLK 767. El alemán tiene «alten oder neuen Lehrer», el latín «patres» y «neoterici».

11 El reconocimiento de un desarrollo doctrinal legítimo — contra la idea de mera conservación del depositum fidei- no tiene que necesariamente conducir a las conclusiones presentadas por Newman en su ensayo sobre el desarrollo de la doctrina cristiana (cosa que volvería la idea de tal desarrollo incompatible con el protestantismo). Para una defensa de que el protestantismo puede — tal vez incluso tiene - que aceptar tal idea de desarrollo, véase Schaff, Philip. The Principle of Protestantism Wipf \& Stock Publishers, Eugene, 2004.

12 BSLK 153.

13 BSLK 152.

14 BSLK 152.

15 BSLK 983 excellentes doctores ex erudita antiquitate.

16 BSLK 1024 veteres ecclesiae doctores. 
Muy distinto es el caso de Melanchthon. Poco después de haber escrito sobre Tomás de Aquino como un «moderno prudente», Melanchthon establece un contraste entre los sentenciarios y Ambrosio ${ }^{17}$. Pero el término "padre» se extiende mucho más adelante que este padre del siglo iv. En efecto, todavía dentro de la Apología, Melanchthon habla de "padres» como Bernardo (muerto en 1153) y Francisco (muerto en 1226). Melanchthon se aleja, pues, de nuestro uso, y trabaja más bien con un concepto de "padres» tan amplio como el de Migne en el siglo xix. Los padres llegan así a una fecha que prácticamente coincide con la del nacimiento de un «moderno prudente» como Tomás de Aquino. Pero éste se encuentra, desde luego, entre los criticados «sentenciarios». El límite de lo admitido parece, pues, empezar a coincidir con Pedro Lombardo, quien vive precisamente entre un «padre» como Francisco y un «moderno prudente» como Tomás de Aquino. ¿Pero a qué lado de la división se encuentra Lombardo? Migne, para volver a la anterior comparación, lo deja al lado de los padres. Para responder a esta pregunta corresponde dirigirse al capítulo de la Apología "Sobre la confesión y la satisfacción", y la crítica que ahí hace Melanchthon al modo en que sus adversarios entienden la penitencia y las obras supererogatorias ${ }^{18}$. Pues tras presentar sus propios argumentos, reclama que para la doctrina de los adversarios no hay respaldo ni en los antiguos autores eclesiásticos, y que ni siquiera Pedro Lombardo habla de las «satisfacciones eclesiásticas» del modo en que lo hacen ellos. Este «ni siquiera» (ne... quidem) parece indicar que en Lombardo habría cabido esperar algo semejante, pero que en este caso no ocurre. Parece pues con toda propiedad una figura límite. Acto seguido, en efecto, habrían venido "los escolásticos», que de la presencia de satisfacciones en la iglesia concluyen que éstas deben tener algún poder para aplacar a Dios.

Nos encontramos, pues, ante un punto en el que los escolásticos son responsabilizados de modo exclusivo por un error, y la explicación ofrecida es muy frecuente en Melanchthon: se habrían confundido cosas espirituales con cosas políticas ${ }^{19}$ (el término "política» incluso es dejado en griego en esta afirmación, enfatizando así lo afirmado). El sentido de tal crítica es que una medida legítima en su condición puramente disciplinaria ("política») es confundida con algo capaz de satisfacer a Dios (justicia espiritual). La terminología más usual con que Melanchthon trata esto, la de una confusión entre la justicia del evangelio y la justicia civil, la trataremos más adelante. Por lo pronto cabe aquí notar que incluso los canonistas son eximidos por Melanchthon de este error, en cuanto la glosa al Decreto de Graciano reconoce que las satisfacciones habrían sido instituidas por disciplina ${ }^{20}$. La escolástica, delimitada de este modo, se presenta así como un fenómeno de decadencia, pero no por haber sido excesiva en su búsqueda de precisión conceptual, sino, por el contrario, por la falta de distinción en un punto relevante.

\section{Aspectos de la controversia}

Nuestra primera sección parece pues arrojar un resultado sencillo, pero que se opone al modo en que la Reforma suele ser entendida tanto por amigos como enemigos: para el Libro de Concordia no hay adversario «medieval» alguno, sino que los primeros

17 BSLK 182. Este contraste entre los sentenciarios y Ambrosio es repetido en BSLK 449-450 como un contraste entre Agustín por una parte, y Tomás y Escoto por otra.

18 BSLK 275.

19 BSLK 277.

20 BSLK 276-7. 
luteranos parecen entenderse como insertos en un capítulo más de la «querella entre los antiguos y los modernos». Dentro de tal querella se parece apostar por un espíritu muy ecuánime de someter a antiguos y modernos a una misma regla, la de ser evaluados a la luz de las Escrituras, y la ecuanimidad se mantiene al menos lo suficiente como para hacer distinciones, estableciendo que entre los modernos hay algunos tolerables. Pero en medio de eso no queda duda de que los luteranos se entienden en una lucha con los antiguos contra los modernos. Puede desde luego discutirse si acaso dicha autocomprensión es correcta, si acaso no son ellos mismos más modernos de lo que reconocen. Pero que su autocomprensión es otra, al menos eso parece fuera de toda duda.

Con eso en mente nos dedicaremos a algunas cuestiones puntuales que permitan evaluar con detalle las controversias. La discusión sobre los sacramentos, que aquí no abordaremos, es uno de los temas que llevan a mayor cantidad de juicios negativos sobre los escolásticos, aunque cabe notar que precisamente ahí lo que prima son no condenas sumarias, sino siempre críticas dirigidas a determinados autores respecto de puntos específicos ${ }^{21}$. En los temas que abordaremos, en cambio, puede grosso modo corroborarse el espíritu constatado hasta aquí. Nos detendremos en primer lugar en la concepción del hombre y de la salvación. Bajo dicho acápite trataremos la acusación de pelagianismo lanzada contra la escolástica, así como la doctrina de la justificación, en particular en cuanto implica una discusión más general sobre la naturaleza de la justicia. En segundo lugar, atenderemos a las relaciones entre teología y filosofía, y a la pregunta por el uso de la razón en cuestiones teológicas. Estos puntos, como es natural, se encuentran estrechamente vinculados, pero esta división puede tener algunas ventajas pedagógicas.

\subsection{Pelagianismo, justificación por la fe y justicia civil}

Comienzo por una acusación muy frecuente no sólo de parte de los reformadores, sino del grueso de la tradición protestante contra la teología medieval, la acusación de pelagianismo o semipelagianismo. Como es bien sabido, el término «semipelagianismo» es una creación moderna. Con frecuencia se fija su creación en la literatura antimolinista de la última década del siglo $\mathrm{XVI}^{22}$. Esto constituye a todas luces un error,

21 La discusión sobre sacramentos es significativa en dos sentidos. En primer lugar, por cuanto nos encontramos con una mayor abundancia de nombres propios, en lugar de referencias generales a la teología precedente (aunque también aquí haya algunas alusiones a «sofistas»). En segundo lugar, porque en esa evaluación más específica se puede constatar de modo sencillo el relativo equilibrio entre tomas de distancia y afirmaciones de continuidad. Consideremos, por ejemplo, los Artículos de Esmalcalda, en los que Tomás de Aquino es criticado por su definición del bautismo. Se defiende ahí la definición agustiniana según la cual «la palabra se suma al elemento, y se tiene un sacramento», contraponiéndola a definiciones de Tomás de Aquino y Escoto, en que desaparecería tal papel primordial de la palabra. Se trata, por cierto, de un caso único en los escritos confesionales, por incluir en cada caso una referencia a la respectiva orden — dominicos y franciscanos—- criticadas junto a sus respectivas cabezas más representativas. Pero cabe notar que cuando se trata de argumentar respecto del bautismo contra otro frente, el anabautista, Lutero no duda en apoyarse en una buena cantidad de autores tardomedievales como «Bernardo, Gerson, Juan Hus y otros», los cuales son además mencionados como «padres de la iglesia» (BSLK 701).

22 Así ocurre, sin documentar la tesis, en un considerable número de obras enciclopédicas del último siglo. Detrás de esta tesis se encuentra con toda probabilidad el artículo de M. Jacquin. "A quelle date apparaît le terme 'Semipélagien'?» en Revue des sciences philosophiques et théologiques 1, 1907, pp. 506-8. Así ocurre, por ejemplo, en el artículo «Semipelagianismo», de Conrad Leyser en Fitzgerald, Allan (ed.). Diccionario de san Agustín Monte Carmelo, Burgos, 2001, que incluso explícitamente afirma que el uso protestante del término sería posterior al de la controversia antimolinista. Tal afirmación debe ser categóricamente descartada a la luz de lo aquí expuesto. 
pues en la Fórmula de Concordia el término ya es usado, rechazando «el falso dogma de los semipelagianos, que enseñan que el hombre puede por sus fuerzas dar inicio a la conversión, pero que no puede ser completada sin la gracia del Espíritu Santo» ${ }^{23}$. Aquí el adversario naturalmente no es el molinismo, sino cierto semipelagianismo tardomedieval. La acusación de semipelagianismo, como la de pelagianismo, es rutinaria, y se ve además apoyada por aquellos autores medievales como Bradwardine que la levantaban contra sus contemporáneos.

Estas acusaciones son, por supuesto, coextensivas con la acusación de que no se ha comprendido la gravedad de la caída del hombre. Sobre dicha caída, en efecto, Lutero afirma que «los escolásticos» sólo han enseñado «error y ceguera ${ }^{24}$. En Melanchthon se encuentran tesis similares. Al comenzar la Apología, caracteriza a los escolásticos como autores que reconocen las enfermedades más leves del hombre, pero no las más graves $^{25}$. La explicación ofrecida es la de haber sido «secuestrados» por una filosofía ajena al cristianismo. Los términos específicos de la acusación son aquí los de haber mezclado la doctrina de Cristo con una filosofía «de la perfección de la naturaleza humana» ${ }^{26}$. En este caso, la difundida concepción según la cual el catolicismo romano implica una visión más optimista y el protestantismo una visión más pesimista de la vida parecería pues encontrarse en lo correcto. Como tendremos ocasión de ver más adelante, no toda interacción con la filosofía es así rechazada; si bien este Aristóteles, interpretado como un simple optimista antropológico, sí resulta problemático para Melanchthon tanto como para Lutero.

¿Pero tiene esta crítica algún blanco específico, o es lanzada de modo indiscriminado? Hay indicios en ambas direcciones. En el capítulo de la Apología sobre el libre albedrío, Melanchthon escribe que «las opiniones pelagianas se enseñan con gran autoridad en las escuelas» ${ }^{27}$. Esta crítica indiferenciada a «las escuelas» puede implicar a toda la tradición tardomedieval. Pero también es una expresión que podría ser susceptible de una lectura más generosa: Melanchthon podría estar aludiendo a lo que a comienzos del siglo XVI, no en el siglo XIII, le pareciera estar siendo enseñado en todas las escuelas. Y efectivamente, cuando hay alusiones concretas, se encuentran casi todas vinculadas al nombre de Gabriel Biel ${ }^{28}$; hay además autores medievales previos a la escolástica, que son expresamente puestos a salvo de la acusación de pelagianismo. Así, Melanchthon escribe que muchos padres como Bernardo y Francisco siguieron un camino de vida, creyendo que era Dios el que los salvaba, pero que sus sucesores creyeron más bien en ese género de vida como medio de salvación ${ }^{29}$. Estamos pues ante algo estructuralmente similar a lo que hemos visto en relación a las satisfacciones: Melanchthon afirma que ciertas prácticas son en un primer paso aceptadas, sin perjuicio para la doctrina, pero que en generaciones siguientes la fe es puesta en tales prácticas, con lo cual se consuma una posición pelagiana.

23 BSLK, 778.

24 BSLK, 434. Lutero cita varios ejemplos de tales enseñanzas, pero ni sus propias afirmaciones en el texto, ni tampoco las notas de sus editores, contienen una referencia a un escolástico, sino sólo una sumamente vaga referencia a Platón y Aristóteles como antecedentes.

25 BSLK 149.

26 BSLK 149 scholastici admiscuerunt doctrinae christianae philosophiam de perfectione naturae.

27 BSLK 311 Quam multa absurda sequuntur ex his Pelagianis opinionibus, quae in scholis magna auctoritate docentur!

${ }_{28}$ Así, por ejemplo, en BSLK 163, la acusación de introducir la distinción entre merito de congruo y de condigno para no parecer abiertamente pelagiano.

29 BSLK 200. 
Esta acusación de pelagianismo puede, en efecto, estudiarse en sus dos polos: en el punto de partida, la visión que se tenga del hombre caído, y el punto que de ahí se sigue, las divergentes comprensiones del proceso de redención. Dirigiendo la mirada a este segundo polo podemos partir por considerar algunas afirmaciones de tipo general sobre la regeneración y el lavado de las culpas. Aquí nos encontramos con palabras dirigidas específicamente contra Tomás de Aquino, por su afirmación según la cual «el ayuno sirve para borrar la culpa». Melanchthon lo comenta simplemente añadiendo que «son palabras textuales de Tomás» ${ }^{30}$. En esta ocasión, en efecto, Tomás de Aquino no es tratado como un caso más "prudente», sino puesto como ejemplo de toda la cohorte de escolásticos que según Melanchthon «no ha dicho nada sobre la fe» que salva, aunque sí hayan hablado sobre la fides historica ${ }^{31}$. Y una vez más, es sobre todo la literatura sentenciaria la que está siendo objeto de crítica: Melanchthon se queja por el «ejército de comentadores de las Sentencias» que no dice nada sobre la regeneración ${ }^{32}$. Con todo, esta crítica incluye cierto reconocimiento de la lucidez ${ }^{33}$, por decirlo así, con que cometen su error, pues cuando atribuyen al amor la capacidad de justificar, entienden que el amor es una obra de la ley ${ }^{34}$, en contraste con quienes interpretarían el llamado a obrar por amor como evangelio. La típica dialéctica luterana entre ley y evangelio pretende precisamente ser una respuesta a este escenario.

Pero si bien el tono general es éste, en al menos una ocasión la discusión se vuelve algo más específica. El contexto es el capítulo de la Apología sobre el pecado original, y en concreto la pregunta sobre si acaso la concupiscencia debe ser vista como algo malo o indiferente. Se trata de un clásico punto de controversia de la época: la ausencia de un apetito desordenado en el estado de justicia original no es vista por los reformadores como producto de un donum superadditum, sino como lo propio de la naturaleza buena creada por Dios; por lo mismo, el estado posterior de concupiscencia es visto como algo de suyo pecaminoso, como la esencia misma del pecado, en contraste con las posiciones según las cuales la concupiscencia se dice pecado no en sentido propio, sino en cuanto es fruto del pecado y causa del pecado. En sí misma, según tal aproximación, no sería por tanto buena ni mala. Contra esto Melanchthon alista aquí a su favor algunos textos de san Agustín contra Juliano, donde es enfáticamente defendido que la concupiscencia no es un adiaphoron ${ }^{35}$. Los adversarios de tal tesis agustiniana se encontrarían precisamente «en las escuelas» y formularían su posición en términos característicamente aristotélicos: diciendo que no somos elogiados ni criticados a causa de las pasiones (según la fórmula de Aristóteles en EN II, 5).

30 BSLK 301. Aquí los editores correctamente identifican S. Th. II-II, q. 147, a.3 c. como el lugar criticado por Melanchthon.

31 BSLK 184. At scholastici ne verbum quidem de hac fide tradunt.

32 BSLK 173.

33 BSLK 204. Se trata, desde luego, de un reconocimiento irónico: scholastici doctores, magni et ingeniosi homines.

34 BSLK 204.

35 La referencia de los editores en BSLK 155 es a Contra Iulianum IV, 9 y a Contra Iulianum Opus Imperfectum V, 5 y VI, 8. Sin embargo, en ninguno de estos lugares aparece el término adiaphoron —usado dos veces por Melanchthon en este párrafo-, ni ninguno de sus equivalentes latinos. Tampoco aparece en el texto aristotélico que citamos algo más adelante, ni en el comentario de Tomás de Aquino al mismo en $S$. Th. I-II q 24 a 1 ad 3. La explicación puede encontrarse en el hecho de que en Juliano la coscupiscencia es descrita como algo puramente natural- $\mathrm{y}$ «natural» desde el siglo XII muchas veces opera como sinónimo de indiferente; así, por ejemplo, en Jean de la Rochelle; al respecto véase Lottin, Odon. Psychologie et morale aux XIIe et XIIIe siècles Abbaye du Mont César, Lovaina, 1942-60. Vol. II, pág. 470. 
Este texto de la Apología es particularmente importante porque en sus tesis de 1536 sobre la justificación, Lutero cita este mismo pasaje aristotélico como algo en lo que los escolásticos buscarían refugio para considerar la concupiscencia como un adiaphoron $^{36}$. ¿Pero qué escolásticos, si es que alguno, enseñaban algo semejante? La edición estándar de los escritos confesionales refiere aquí a una cuestión de la I-II de la Suma Teológica de Tomás de Aquino; pero tal referencia constituye un caso ejemplar de la pobreza que hasta hoy sigue caracterizando la edición de estos documentos, al menos en lo que respecta a su relación con la tradición precedente. Pues Tomás de Aquino cita, en efecto, dicha afirmación de Aristóteles, pero entre las objeciones; no en su propia toma de posición, la cual enfatiza más bien lo contrario: que, en cuanto se encuentran sujetas a la razón y a la voluntad, que es como se encuentran en cada acto concreto del hombre, las pasiones sí se dicen buenas o malas. Los editores modernos de la Apología ciertamente yerran. Pero esto no significa que Melanchthon estuviera atacando a un hombre de paja: la tesis rechazada se encuentra, por ejemplo, muy presente en el marco del internalismo del siglo xII, donde la tesis de la primacía de la intención — por ejemplo en un autor como Abelardo- tiene por tesis paralela no sólo la indiferencia de la obra externa, sino también la de las inclinaciones ${ }^{37}$. Lo que aquí tenemos es, pues, un elocuente ejemplo de cómo la adecuada identificación de sus reales adversarios haría ganar fuerza - por hacer más sólido su diagnóstico- a las posiciones de los reformadores. Tal adecuada identificación es, sin embargo, algo inusual en ellos, y rara vez notado por los modernos editores de sus obras.

Ahora bien, al explicar Melanchthon por qué los escolásticos habrían caído en este error, afirma que sería por seguir un uso del lenguaje que entre los filósofos no era problemático. «Entre los filósofos», explica Melanchthon - y tal expresión se refiere a los antiguos- «este tipo de expresiones hacen referencia al juicio civil, no al juicio de Dios» ${ }^{38}$. Y en tal lugar, afirma Melanchthon, está bien dicho: en el juicio civil sólo preguntamos si ha habido obra externa, y de lo contrario declaramos inocente al inculpado. «Pero los escolásticos mezclan intempestivamente la doctrina filosófica o civil con el evangelio ${ }^{39}$. Tales afirmaciones sobre la filosofía —evidentemente problemáticas— nos conducen a nuestra última sección, en que consideraremos la relación de los escritos confesionales con la tradición precedente en lo que se refiere al uso de la razón.

\subsection{Teología, filosofía y apelación a la razón}

En los puntos anteriores nos hemos encontrado con casos emblemáticos de enfrentamiento entre lo que parece ser el «aristotelismo» de los escolásticos y el «agustinismo» de los reformadores. La contraposición entre ambos movimientos suele, en efecto, con frecuencia ser presentada en términos de esas respectivas adhesiones al filósofo griego y al padre africano. Hoy tal tipo de contraste se encuentra por supuesto en merecido descrédito, tanto entre los medievalistas como entre los estudiosos de la Reforma, dada la conciencia que hemos tomado, por ejemplo, del agustinismo de Tomás de Aquino ${ }^{40}$,

36 WA 39/1, 85 .

37 Al respecto véase Svensson, M. «Indiferencia, ambivalencia y primacía de la intención. Agustín en el Scito te ipsum de Abelardo» Kriterion 53, 2012.

38 BSLK 155-156.

39 BSLK, 56.

40 Véase Dauphinais, M., et al. (eds.) Aquinas the Augustinian CUA Press, Washington, 2007. 
pero también del aristotelismo de muchos protestantes de primera generación ${ }^{41}$. La discusión sobre el carácter indiferente de la concupiscencia, que acabamos de considerar, sirve de excelente punto para ilustrar el tipo de apoyo que tenía la contraposición a la que estudios más antiguos nos tenían acostumbrados: Aristóteles, en efecto, ha aparecido aquí en manos de los escolásticos para defender una posición en un debate teológico, y la principal autoridad que los reformadores tienen para contraponerle es la de Agustín; pero no deja de resultar irónico que el término técnico en discusión —adiaphora (cosas indiferentes) — sea una noción que desempeña un papel virtualmente nulo en los mismos Aristóteles y Agustín ${ }^{42}$.

Sea como fuere, este tipo de situaciones explican parte de las invectivas protestantes contra quien para los escolásticos es «el Filósofo» (una designación, por cierto, que muchos escolásticos protestantes continúan usando para Aristóteles $)^{43}$. Y si bien estas invectivas son mucho más inusuales que lo que la posterior literatura nos ha hecho creer, de este modo se ha creado también una imagen respecto de cuál sería la relación del protestantismo no sólo con Aristóteles, sino en general con las apelaciones a la razón. En efecto, es muy común afirmar que el protestantismo implicaría una menor confianza en la razón que la que se encuentra en toda la tradición teológica precedente ${ }^{44}$. Tal como en otros tópicos, la mirada a los escritos confesionales conduce aquí a un juicio más sobrio. En toda la obra hay solo dos textos que parecen contener una visión negativa de la razón. Uno de ellos no permite concluir mucho, pues si bien es una alusión a la «vana razón humana y la filosofía», es en medio de un pasaje que no parece más que recoger el mensaje de I de Corintios respecto de cómo se ve la sabiduría de Dios a los ojos de un mundo perverso ${ }^{45}$. Tales afirmaciones se encuentran por supuesto presentes a lo largo de toda la tradición cristiana, tal como las críticas a la mera curiositas $^{46}$, y no permiten concluir nada en particular respecto del protestantismo. La otra mención se encuentra en la Solida Declaratio de la Fórmula de Concordia, pero no es un texto de los autores de la misma, sino un texto de Lutero que estos autores citan en medio de su propia exposición. Ahí, éste habla de la «vieja bruja, doña razón». Esto parecería confirmar la interpretación según la cual si no el protestantismo en general, al menos Lutero sería un irracionalista. Pero significativamente, este texto suyo no hace alusión a algún presunto abuso de la razón por parte de los escolásticos, sino que es una alusión a otro reformador protestante, Zwinglio, por su invocación de la alloiosis o comunicación de propiedades para rechazar una lectura literal de las palabras «éste es mi cuerpo» ${ }^{47}$. Si tenemos aquí una crítica a la razón, es pues contra el uso de la razón que hay en un

${ }_{41}$ Para el estado de la cuestión, aunque limitado a Melanchthon (quien no debiera en esto ser considerado excepcional), véase KURopKA, N. «Philip Melanchthon and Aristotle» en DingEL, I., et al. (eds.) Philip Melanchthon. Theologian in Classroom, Confession and Controversy Vandenhoeck \& Ruprecht, Göttingen, 2012. págs. 19-28.

42 En Aristóteles a lo sumo puede mencionarse la vaga apelación a la noción en EN V, 7; para Agustín véase el artículo citado en nota 41.

43 Al respecto véase Theo Pleizier y MaArten Wisse, «As The Philosopher Says: Aristotle» en van Asselt, Willem, J. (ed.) Introduction to Reformed Scholasticism Reformation Heritage Books, Grand Rapids, 2011.

44 Véase, por ejemplo, la caracterización reciente en Belda Plans, J. Historia de la teología Palabra, Madrid, 2010. págs. 152-156. Su exposición, como tantas otras, logra mantener esta imagen precisamente por la omisión de los escritos confesionales.

45 BSLK 874.

46 BSLK 225.

47 BSLK 1029. 
reformador más influenciado por el humanismo renacentista, no contra la tradición intelectual previa del cristianismo.

Esto no significa que la escolástica no sea criticada por algunas de sus prácticas intelectuales. Pero precisamente no por un uso abusivo de la razón en el sentido de un uso excesivo de la misma. En efecto, si ocasionalmente se encuentra en estos escritos la designación de la escolástica como una cierta sofística ${ }^{48}$, esto implica una crítica por un uso deficiente, no simplemente excesivo de la razón. Y ésta es la tendencia general que se puede constatar a lo largo de los escritos confesionales. Así, cuando hay queja por el recurso a la filosofía, no es por haberla usado, sino literalmente por haberla mezclado (admiscuisse) con la teología, y no por cualquier mezcla, sino por una descrita como excesiva (plura... quam satis erat) ${ }^{49}$, lo cual implica la posibilidad de una interacción adecuada. En otros casos, de hecho, la situación llega a invertirse, de modo que los adversarios son retratados como gente que no da lugar a discusión racional, sino que afirma su posición como ley ${ }^{50}$. Cabe notar, por cierto, que esto nunca es formulado en términos de una queja respecto del hecho de que el dogma esté siendo invocado con fuerza de ley, sino que es siempre formulado en términos de una queja contra la absolutización de la posición de ciertas escuelas o teólogos. Es más, en la Apología se encuentra incluso una positiva alusión — con expresa referencia al Fedro platónico- al amor que Sócrates declara tener por las divisiones y uniones (esto es, por el trabajo dialéctico), y se critica a los adversarios por no seguir este consejo socrático ${ }^{51}$. En medio de la crítica a los «excesos» de la escolástica, se encuentran pues críticas — justificadas o no, nos importa aquí lo que revelan sobre la autocomprensión de los reformadores- que parecen apuntar a que ésta fue insuficientemente escolástica. Así, lo que en realidad tenemos es una delimitación respecto de dos posibles extremos, dejando un vasto campo en el que se puede deliberar prudencialmente respecto de cuánto y cómo usar la razón.

Pero cabe insistir en que en los escritos confesionales el uso de la razón suele ser defendido con considerable insistencia. Notémoslo brevemente en torno a dos puntos. En primer lugar, es explícitamente recogida la legitimidad del uso de lenguaje filosófico para la explicación de posiciones teológicas. Así ocurre, por ejemplo, a propósito de la discusión sobre la naturaleza caída. La Fórmula de Concordia es enfática en este punto en su condena de Matthias Flacius, quien había hablado de la imagen de Dios como reemplazada por la imagen del diablo, y del pecado original como esencia del hombre ${ }^{52}$. Contra tal posición los autores de la Fórmula de Concordia sostienen la necesidad de afirmar categóricamente que el pecado no puede ser una sustancia. Es más, que todo lo real es sustancia o accidente es presentado como axiomático para la teología (indubitatum certissisimumque axioma in re theologica $)^{53}$; apenas podría haber un reconocimiento más claro de la legitimidad de las herramientras conceptuales de Aristóteles para el trabajo teológico. Si bien se rechaza que tal lenguaje sea usado en los sermones, acto seguido se afirma que es lícito hacerlo en las escuelas, donde tal vocabulario es

48 BSLK 225.

49 BSLK 232.

$50 \quad$ BSLK 331 non est quaerenda ratio, sed lex esto, quidquid dicunt theologi.

51 BSLK 353. La referencia es a Platón, Fedro 50, 266b. "Y de esto es de lo que soy yo amante, Fedro, de las divisiones y uniones, que me hacen capaz de hablar y de pensar. [...] Por cierto que aquellos que son capaces de hacer esto - Sabe dios si acierto con el nombre-les llamo, por lo pronto, dialécticos».

52 Para una defensa de Flacius, véase Olson, O. Matthias Flacius and the Survival of Luther's Reform Lutheran Press, Minneapolis, Minn., 2011.

53 BSLK 862. 
ampliamente conocido ${ }^{54}$. En segundo lugar, la Fórmula llama a cuidarse del uso de expresiones generales sobre la involuntariedad de la conversión, que no vayan acompañadas de la debida explicación (declaratio) ${ }^{55}$. Y, aunque sea ocasionalmente, para tal adecuada explicación se apela justamente a los escolásticos medievales. Esto ocurre, por lo demás, en relación con una materia tan central como la cuestión de la relación de la fe con el intelecto y la voluntad. En efecto, en caso de que algún «sofista» niegue que la fe, la cual radica en el intelecto, pueda salvar, argumentando que la justicia se encuentra en la voluntad y no en el intelecto, Melanchthon lo remite al hecho de que «en sus propias escuelas» se enseña que la voluntad impera al intelecto para que asienta a la Palabra de Dios ${ }^{56}$. Ocasionalmente, al menos, tenemos pues también de parte de los reformadores toma de posición a favor de unos escolásticos contra otros.

Esto debe por supuesto ser equilibrado reconociendo la existencia de una preocupación de los reformadores por una literatura escolástica que no contribuye a la piedad. Ahora bien, Melanchthon menciona esto en la Apología no como una preocupación exclusiva de los protestantes, sino precisamente en un momento en que habla del carácter no excepcional de las críticas de Lutero, del hecho de que esta crítica contaba con amplios antecedentes: «nosotros mismos —escribe Melanchthon sobre su propia época de estudiante en Tubinga- oímos a excelentes teólogos manifestar deseo por más moderación en la doctrina escolástica, que tiene más de disputa filosófica que de piedad ${ }^{57}$. Dicho trasfondo explica la peculiar afición de los reformadores por ciertos medievales muy específicos -Gerson entre los luteranos ${ }^{58}$, Bernardo en el caso de Calvino ${ }^{59}$-, y el llamado a, ante la controversia infructífera, reestablecer «los juicios de la Escritura y de los padres» ${ }^{60}$ y retener, en la medida de lo posible, las «formulaciones usuales de la doctrina ${ }^{61}$.

\section{Conclusión}

Una atenta consideración de los escritos confesionales, que por siglos desempeñaron un papel fundamental en la autocomprensión de las iglesias protestantes, y que en algunos casos lo siguen desempeñando ${ }^{62}$, entrega como resultado una imagen mucho más matizada de la relación de la Reforma con la tradición intelectual precedente. Ciertamente hemos encontrado también en los escritos confesionales acusaciones imprecisas, pero en muchas ocasiones también algunas de carácter más preciso.

54 BSLK 775.

BSLK 779.

56 BSLK 219 remite acertadamente a S. Th. I, q. 56, a. 3 c. como ejemplo de esta posición.

BSLK 326.

58 BSLK 410.

59 Al respecto véase Lane, A.: John Calvin. Student of the Church Fathers. T \& T Clark, Edinburgh, 1999.

60 BSLK 153. gravissimas sententias scripturae et patrum, obrutas sophisticis rixis theologorum recentium, repurgamus et in lucem restituimus.

61 BSLK 143.

62 Para su vitalidad contemporánea véase, para el caso luterano Kolb, Robert. Confessing the Faith Concordia Publishing House, Saint Louis, 1991 y, para el caso reformado, Clark, R. Scott. Recovering the Confessions P \& R Publishing, Philipsburg, 2008. 
Cuando se da tal precisión, el juicio negativo más fuerte suele recaer sobre la escolástica tardomedieval cronológicamente más cercana a los reformadores. Como hemos visto, esto tiene que ver con un recurrente argumento de Melanchthon, según el cual cuestiones que son adoptadas en una generación son recogidas en la siguiente con un sentido distinto. Así, los fundadores de las órdenes mendicantes son interpretados como figuras que adoptan un género de vida con conciencia de su propia dependencia de la gracia, mientras que la generación siguiente adoptaría el mismo género de vida como camino de salvación; asimismo, prácticas reconocidas en una generación por su valor disciplinario, en la siguiente serían recogidas por su valor salvífico. Piénsese lo que se piense sobre esta explicación, ella naturalmente tenderá a dejar caer un dictamen más severo sobre los autores más recientes. Según hemos podido constatar, esto implica un juicio por lo general negativo respecto de los autores cronológicamente más cercanos, como Gabriel Biel, y en general positivo sobre los cronológicamente más lejanos, como los anteriores a Pedro Lombardo. El mismo Lombardo, así como Tomás de Aquino, parecen quedar en un territorio intermedio; pero precisamente ese territorio intermedio permite que sobre ellos haya juicios más diferenciados, que sus posiciones sean evaluadas caso a caso.

Conclusiones como éstas son fuera de toda duda importantes para nuestra visión del papel desempeñado por la Reforma en la historia intelectual. Un mínimo de familiaridad con los escritos confesionales basta, en efecto, para que interpretaciones primordialmente rupturistas de la misma se vengan abajo. Pero los problemas no se encuentran únicamente en la extendida omisión de estos escritos cuando se considera el periodo, sino que se encuentra también dentro de los mismos: urge, en efecto, una edición de los textos confesionales hecha desde la conciencia de la continuidad con la tradición precedente.

Universidad de los Andes

Manfred Svensson

Instituto de Filosofía,

Avda. San Carlos Apoquindo,

2200, Las Condes (Santiago), Chile

msvensson@uandes.cl

[Artículo aprobado para publicación en noviembre de 2014] 
